J. Reprod. Fert. (1971) 24, 109-110

\title{
THE FERTILITY OF EWES AFTER IMPLANTATION OF DUMMY PRESSURE TRANSDUCERS IN THE UTERINE WALL*
}

\author{
A. R. LEHRER AND H. SCHINDLER \\ The Volcani Institute of Agricultural Research, Rehovot, Israel
}

(Received 26th May 1970)

Foreign bodies inserted into the uterine lumen of ewes act as contraceptives (Hawk, 1965, 1967). A sensor used for monitoring uterine contractions in the non-pregnant ewe in vivo should not, therefore, be implanted in the lumen when minimal interference with normal reproductive function is desired. The following experiments were carried out in order to test the possibility of maintaining the capacity to conceive by implanting the sensor in the uterine wall rather than in the lumen.

Dummies were made of perspex in the shape and size of the real pressure transducers which were to be used (Text-fig. 1). The uteri of cycling, nonlactating, Awassi ewes were exposed at laparotomy and incisions about $1 \mathrm{~cm}$ long were made on the dorsal wall through the serosa into the myometrium. An additional incision at right angles to the first was made in the myometrium beneath the serosa. Dummies were inserted in the incised myometrium-with the base of their discs orientated towards the uterine lumen and their stems pointing towards the exterior-and fixed there with catgut ligatures around their stems. One to three dummy transducers were implanted in the uterine body and/or horns of each of eighteen ewes, but no more than one dummy in each of these parts. The leads of the dummies were pulled through the surgical opening in the abdomen and fixed to the skin.

Hand-matings were performed during the post-operational oestrous periods and the ewes were slaughtered 1 month, or later, after the operation for examination of the position of the implanted dummy transducer and for pregnancy diagnosis. Histological preparations were made from segments of the uterine wall containing the dummy transducers, using haematoxylin-eosin or Gomori's trichrome staining.

All the implanted dummy transducers were recovered at autopsy. In twelve ewes, one or more transducers migrated into the uterine lumen and were found beneath the point of implantation. None of these ewes had become pregnant, including those in which the migration had occurred in the horn contralateral to the ovulating ovary. In one ewe which aborted 24 days after mating, one of three implanted transducers had migrated into the lumen. In five ewes, all the dummy transducers remained in the uterine wall and three of these

* Contribution from The Volcani Institute of Agricultural Research, Bet Dagan, Israel. 1970 Series, No. 1717-E. 
ewes, which had one or three transducers in the uterine wall, were found to be pregnant.

Histological examination of the uterine segments which contained the transducers revealed their position in relation to the different layers of the uterine wall, as well as the reaction of the tissue to contact with them. The discs of the transducers were totally embedded in the myometrium (Pl. 1, Figs. 1 and 2), or the endometrium (P1. 1, Figs. 3 and 4) or traversed both layers. The occurrence of pregnancy did not depend upon the position of the transducer inside the uterine wall. Only slight changes were found in the uterine tissue and these were limited to the contact zone. In such areas, some strands of

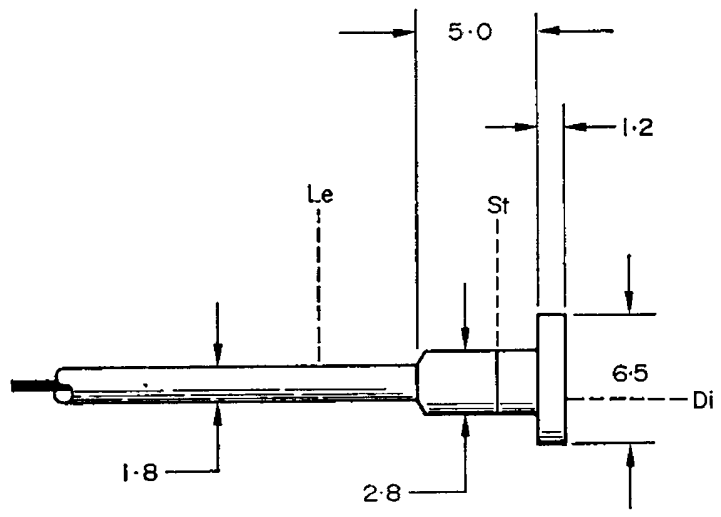

TEXT-FIG. 1. Shape and dimensions (in $\mathrm{mm}$ ) of the dummy pressure transducer. Le-lead; St-stem; Di-disc.

connective tissue were formed, which were slightly infiltrated with mononuclear inflammatory cells. Lymphocytes and plasma-cells, as well as fibroblasts, were also found scattered in other parts of the myometrium. Very small sterile abscesses were caused by the catgut ligatures.

It can be seen from the results that foreign bodies, even as small as those used in our work, prevent pregnancy when they migrate into the uterine lumen. On the other hand, when they remain in the uterine wall they do not necessarily interfere with fertilization or with the early stages of gestation.

This investigation was supported by a grant from the U.S. Department of Agriculture under P.L. 480. The authors are indebted to Dr A. Shomroni for advice and help in the surgical work and to Dr Hanna Broda and Dr T. Nobel for helpful advice and discussion on the histological aspects. The valuable help of Ora Kempenich-Pinto and the technical assistance of Sara Shalom and Y. Dimmermann are gratefully acknowledged.

\section{REFERENCES}

HAwK, H. W. (1965) Inhibition of ovum fertilization in the ewe by intra-uterine plastic spirals. $\mathcal{F}$. Reprod. Fert. 10, 267.

Hawk, H. W. (1967) Investigations into the anti-fertility effect of intra-uterine devices in the ewe. 7. Reprod. Fert. 14, 49. 


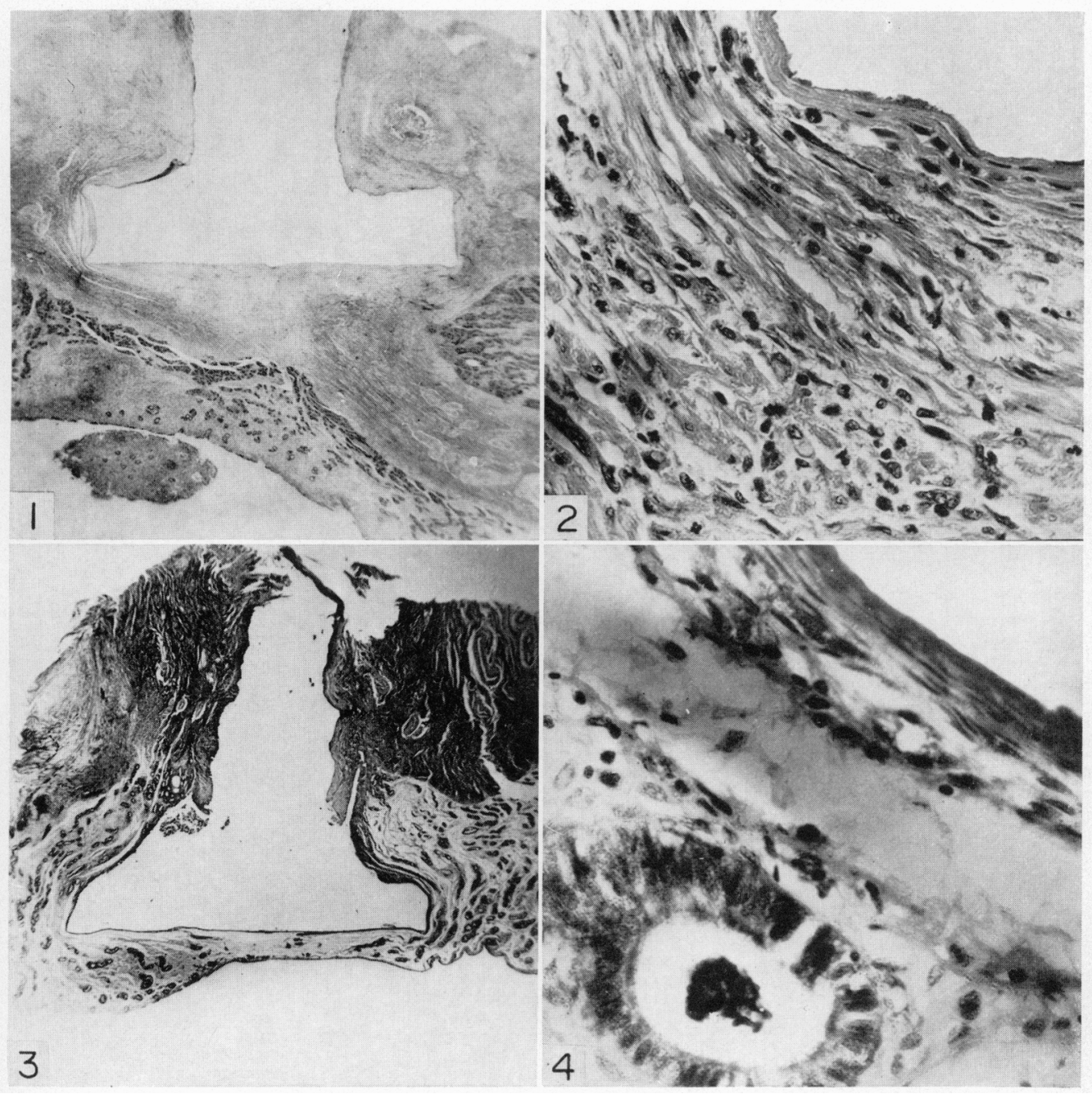

Histological sections of the uterine segments which contained dummy transducers.

Fic. 1. Dummy transducer embedded in the myometrium. H \& E. $\times 8$.

Fig. 2. Contact zone between dummy transduccr and myometrium. $\mathrm{H} \& \mathrm{E} . \times 4.50$.

FIG. 3. Dummy transducer embedded in the endometrium. Gomori's trichrome. $\times 8$.

Fis. 4. Contact zone between dummy transducer and endometrium. Gomori's trichrome. $\times 450$. 